\title{
Time management in operating rooms (ORs) - a retrospective study to evaluate estimated and objective durations of surgical procedures in the field of ENT
}

\section{Lena Zaubitzer}

Universitatsklinikum Mannheim

\section{Annette Affolter}

Universitatsklinikum Mannheim

\section{Sylvia Büttner}

Universitatsklinikum Mannheim

\section{Sonja Ludwig}

Universitatsklinikum Mannheim

\section{Nicole Rotter}

Universitätsklinikum Mannheim

\section{Claudia Scherl}

Universitätsklinikum Mannheim

\section{Sonia von Wihl}

Universitatsklinikum Mannheim

\section{Weiß Christel}

Universitatsklinikum Mannheim

Anne Lammert ( $\nabla$ anne.lammert@umm.de)

Universitatsklinikum Mannheim

\section{Research article}

Keywords: Surgery, time duration, surgeon, operating room, OR

Posted Date: June 9th, 2020

DOI: https://doi.org/10.21203/rs.3.rs-29804/v1

License: (c) (1) This work is licensed under a Creative Commons Attribution 4.0 International License. Read Full License 


\section{Abstract}

Background Accurate planning of operating times in a surgical clinic is essential. High capacity utilization of operating rooms (ORs) is necessary for economic efficiency. Variable working hours of different team members on a surgical team (such as the anesthesiologist, surgeon, and OR-assistant) must also be respected. In this regard, incorrect planning may lead to conflicts between team members, thus disturbing daily work routine. Most planning of operating times is performed by surgeons. Here, objective and estimated times by surgeons were compared to detect sources of error. Methods In a retrospective analysis, durations of 1809 operations under general anaesthesia (22 different types) by 31 surgeons (12 specialists $(S)$ and 19 residents $(R)$ ) of the ear nose throat department at Mannheim University Medical Centre were compared. Incision to suture and preparation and post-processing times of 10 specialists and 17 residents estimated based on questionnaires were compared to objective times. Both comparisons were analyzed by Mann-Whitney-U-tests. Results Comparison of objective times of surgical action showed significant differences between specialists and residents in 6 of 15 types of surgeries. Post-processing times estimated by specialists deviated from objective times in 2 out of 22 surgery types. Post-processing times estimated by residents deviated in 7 out of 15 types. Specialists misjudged incision to suture times in 7 of 22 surgery types, and residents misjudged in 3 out of 15 . Preparation times estimated by specialists deviated from objective times in 16 of 22 types of surgeries and in 7 out of 15 estimated by residents. Conclusions A surgeon's routine must be considered to estimate operating times. Specialists underrated the preparation and post-processing and overrated incision to suture times. Residents underestimated all of these times. Preparation and post-processing times must be considered in the planning and, ideally, determined together with anesthesiologists and OR-assistants.

\section{Background}

Between 1995 and 2006, health expenditures increased 2.5\% per year. The most cost-intensive institutions are hospitals. Personnel and material costs of hospitals particularly increased between 1995 and 2006, which both rose by approximately 39\% [1]. Health expenditures are increasingly financed by private households and private organizations. Furthermore, investment in hospitals by federal states decreased by over 20\% between 2001 and 2011 [1]. These circumstances can only be counteracted by cost minimization, increasing revenues and process optimization. The operating department is an essential part of surgical patient care, but, along with intensive care units, it is also a very cost-intensive division. However, it is one of the main sources of revenues of hospitals [2,3]. The objective of operating room (OR) management must be optimal use of this important source of revenue. The three most important resources in OR management are the OR itself, time and personnel. Their utilization must be optimized to realize maximal profit by operating departments [4]. Thus, one of the most important parts of OR management is the planning of surgery durations. An efficient utilization of ORs can only be assured by accurate planning of OR times. Inefficiency is caused by diverging surgery durations (either too long or too short), which result in rescheduling, idle time and overtime [5], leading to increased 
personal costs and patient dissatisfaction. This leads to overtime hours for the surgeons as well as other occupational groups and specific fields that have to work overtime in consequence of inaccurate planning. This in turn has the potential for conflicts between different team members in the OR. Studies also revealed that different persons on a surgical team partly represent various interests and pursue different goals. This is also caused by the fact that a surgical team is composed of different individuals with divergent values. Moreover, it is a multidisciplinary group of people with different organizational structures within individual occupational groups. Furthermore, efficiency and economy are not among the most important goals of every team member. All these factors abet conflicts. Conflicts in turn result in employee dissatisfaction and hence reduced productivity because employee satisfaction correlates with productivity [6]. Therefore, good planning is important to reduce potential conflicts. OR planning is made on the basis of estimated durations. It must be noted that the OR scheduler is influenced by many factors and mostly does not act on economic rationality [5]. The planner sometimes does not know the patient personally. In consequence, important facts potentially influencing operating times may be missing. It is important that the planner obtains information about the estimated operating time from the surgeon who better knows the patient. Moreover, non-technical skills that are important for surgeons, such as communication, preparation and planning, are sometimes missing. All these skills are important for a successful surgery as well as for accurate planning $[5,7]$.

There are many potential sources of errors in surgery scheduling. The main objective of our research was to disclose general false estimation of durations. There are different time durations in ORs, which have to be taken into account. First, there is the duration between the patient entering the OR and the surgeon's arrival. Then, there is the setup duration, which is the time between the patient's arrival at the $\mathrm{OR}$ and the start of surgery. Included in the setup time is surgical preparation, i.e., the time from the beginning of the patient's preparation, which is performed by the surgeon, to the start of surgery. The incision to suture time defines the duration between the incision (for a surgical procedure) and the end of the suture. After this, the post-processing time begins. It ends when the patient leaves the OR.

Here, we also included surgical post-processing time, which is the time from the end of the suture to the end of all surgery-related activities done by the surgeon. Another important time encompasses the duration between the patient entering and leaving the OR [8].

Moreover, the practical experience of the surgeon has to be considered. Recent studies have already revealed that surgeries are significantly longer with residents being involved [9]. It is generally accepted that surgical training is associated with increased surgical duration. Training the next generation of surgeons is a fundamental part of an effective health care system. Teaching surgical residents is associated with decreased operative efficiency owing to the time needed to give instructions by a specialist and due to slower operative speeds of trainees. The duration of a surgical residency, which takes several years, can result in substantial cumulative inefficiency, impacting the cost as well as access to limited surgical resources. Thus, another aim of our study was to determine which kind of operating times are prolonged when operations are conducted by residents. For the supervising specialists, it might 
be interesting to know for which surgical procedures residents need more time. This information can help save time by better supporting residents during these procedures.

\section{Methods}

In a retrospective study, time durations of 1809 operations under general anaesthesia were analyzed. All surgeries were carried out between the 1st of January and 31st of December 2018 at the ENT Department at Mannheim University Medical Centre. The analysis comprised 22 different types of surgeries performed by 31 surgeons (12 specialists (S) and 19 residents (R)). Residents conducted 627 surgeries and specialists 1182 . Initially, data of 1873 operations were collected, but 64 operations were excluded from the analysis later on because of the combination of various types of procedures in one case. Time durations were gathered from the regular perioperative time registrations documented for every surgery with the aid of SAP NETWEAVER 7.0. Various types of time durations were extracted from this documentation. 1. the median time between the surgeon's entrance and patient's entrance in the operating room, 2. setup time, 3. surgical preparation, 4. incision-to- suture time, 5. post-processing time and 6. surgical post-processing time. Furthermore, based on these durations have been assessed: 7 . the whole operating room time (between patient's entrance into OR and leaving the OR), 8 . the sum of setup and surgical post-processing time, 9 . the sum of surgical preparation and surgical post-processing time and sum of incision to suture and surgical preparation and post-processing time and 10 . the median values for each of these time intervals were compared between Rs and Ss, separately for different kinds of operations. The comparison was done for the following different types of surgeries: extirpation of a cervical lymph node $(n=65)$, midface reconstruction after bone fractures $(n=39)$, panendoscopy including microlaryngoscopy $(n=378)$, one-sided neck-dissection $(n=13)$, endonasal endoscopic sinus surgery $(n=213)$, nasal septoplasty $(n=150)$, septorhinoplasty $(n=170)$, stapes surgery $(n=9)$, submandibulectomy $(n=12)$, tonsillectomy $(n=141)$, tracheostomy $(n=40)$, tympanoplasty $(n=146)$, tonsillectomy with uvulopalatopharyngoplasty $(n=63)$, intracapsular tonsillectomy $(n=110)$, and superficial parotidectomy $(n=55)$. Overall, the comparison was done for $n=1604$ surgeries. Some types of surgeries, which were conducted by specialists only, were excluded from this comparison. Among the excluded surgeries were 94 implantations of a cochlear implant, 32 implantation of hypoglossal nerve stimulator, 17 tumor excisions and subsequent reconstruction with a skin flap, 13 mastoidectomies, 17 sialendoscopies, 22 tumor excisions with neck dissection and 10 total parotidectomies. Altogether, $n=205$ surgeries were performed by specialists only.

Moreover, estimated operating times were requested of 10 specialists and 17 residents with the aid of a questionnaire. Three specialists did not receive a questionnaire or did not answer it for any reason. One specialist who filled out the questionnaire did not perform surgery in the daily routine but was involved in operating time scheduling. Two residents could not obtain a questionnaire, because they had left our department in the meantime. Surgeons estimated their own operating room times, average operating room times of all surgeons, and set- up and post-processing times for the different types of surgery mentioned above. Then, times estimated by specialists were compared to the residents' estimations. Moreover, the median values of estimated durations were checked against the median value of effectively 
taken (objective) operating room times. These comparisons have been done separately within the group of Rs and within the group of Ss.

For all comparisons between two groups, Mann Whitney $U$ test has been used. A p-value less than or equal to 0.05 was considered statistically significant. All statistical analyses were conducted with the aid of SAS software, release 9.4 (SAS Institute Inc., Cary, North Carolina, United States).

The study was approved by the ethics committee II of Ruprecht-Karls-University, Heidelberg, Medical Faculty Mannheim.

\section{Results}

The comparison of objective OR times of residents and specialists showed significant differences for various types of surgeries (tables 1 and 2). There was a significant difference in surgical post processing time after the extirpation of a cervical lymph node between residents and specialists $(p=0.006)$, with residents taking significantly more time. Time between the patients and thesur $\geq$ ons entrance into the operating room was somewhat longer for the residents $(p=0.030)$.

Comparing the OR times of panendoscopy including microlaryngoscopy, significant time discrepancies between residents and specialists could be ascertained for the time between the surgeon's entrance and the patient's entrance into the operating room $(p=0.007)$. Differences were also observed in surgical preparation time $(p<0.001)$, incision to suture time $(p<0.0001)$, post-processing time $(p=0.025)$, entire operating room time $(p=0.001)$, entire duration of surgical action $(p=0.012)$ and the sum of incision to suture time and time of surgical action $(p<0.0001)$.

Except for arrival time to the OR and post-processing time, durations of specialists were significantly shorter than those of residents.

Regarding sinus surgery, the study revealed significant time differences regarding the time between entering of the surgeon and patient in the OR $(p=0.018)$, incision to suture time $(p<0.0001)$, entire OR time $(p<0.0001)$ and the sum of incision to suture and surgical preparation and post-processing time $(p<0.0001)$. As before, residents were more on schedule when they entered the operating room, but they operated slower than the specialists.

The comparison of time required by residents and specialists performing nasal septoplasty showed significant disparity concerning the time between the surgeon $s$ and thepatients entrance to the $\mathrm{OR}$ $(p=0.033)$, incision to suture time $(p<0.0001)$, whole operating room time $(p<0.0001)$ and the sum of setup and post processing time $(p=0.011)$ as well as the sum of incision to suture time and time of surgical action $(p<0.0001)$. Furthermore, in this case, specialists arrived later to the OR but took less time for all the other actions.

Moreover, considering tonsillectomy, there were significant differences between residents and specialists in incision to suture time $(p<0.0001)$, whole OR time $(p<0.0001)$ and the sum of incision to suture time 
and time of surgical action $(p<0.0001)$. All time durations were significantly longer when the surgery was performed by residents.

In addition, the time between entering of the surgeon and patient into the operating room (entrance time) $(p=0.009)$, setup time $(p=0.007)$, incision to suture time $(p=0.002)$, post-processing time $(p=0.015)$, whole operating room time $(p=0.004)$, time of surgical action $(p=0.040)$ and the sum of incision to suture time and time of surgical action $(p=0.001)$ differed significantly for tonsillectomy with uvulopalatopharyngoplasty depending on whether it was performed by residents or specialists. In addition, residents entered the operating room earlier but took longer surgery times than specialists.

Analyzing operating room times of intracapsular tonsillectomies, residents took significantly more time for incision to suture $(p<0.0001)$, whole OR time $(p<0.0001)$, and the sum of incision to suture and surgical action $(\mathrm{p}<0.0001)$.

Finally, there was a significant difference in the post processing time after lateral parotidectomies of residents compared to specialists $(p=0.002)$. In this case, post-processing times of specialists were longer.

For some surgical procedures (Midface revision after bone fractures, submandibulectomy and tracheostomy) no statistically significant differences could be found. This may partly be attributed to the rather small sample sizes of the relevant subgroups.

In summary, specialists often take more time until they enter the OR, but then they perform surgeries faster than residents.

Residents and specialists also differ sometimes in their time estimates (table 3). When asked about the average incision to suture time of all surgeons, estimations were significantly different in the case of implantation of hypoglossal nerve stimulator $(p=0.034)$, midface revision after bone fractures $(p=0.010)$, microlaryngoscopy with panendoscopy $(p=0.028)$, tonsillectomy and lateral parotidectomy $(p=0.036)$.

In regard to post-processing time, significant variable durations were presumed for implantation of cochlear implant $(p=0.041)$, midface reconstruction after bone fractures $(p=0.020)$, submandibulectomy $(p=0.018)$, tumor excision with neck dissection $(p=0.023)$ and total parotidectomy $(p=0.040)$.

Estimated durations of preparation time by residents and specialists only differed significantly in terms of implantation of a stimulator of hypoglossus nerve $(p=0.021)$ and total parotidectomy $(p=0.040)$.

There were significant differences between self-estimation of surgery times and objective times for the following procedures: midface revision after bone fractures $(p=0.005)$, septoplasty $(p=0.021)$, tonsillectomy $(p=0.022)$, tracheostomy $(p=0.016)$, tonsillectomy with uvulopalatopharyngoplasty $(p=0.012)$ and intracapsular tonsillectomy $(p=0.006)$. 
Specialists always estimated longer durations than residents, except for their own OR time. Concerning their own OR time, specialists expected less time than residents for septoplasty, tonsillectomy, tracheotomy and tonsillectomy with uvulopalatopharyngoplasty.

A comparison of the estimated and effectively measured OR times by specialists revealed biased estimations, especially of preparation time and incision to suture time, and rarely also of post-processing time. Specialists underestimated post-processing time only for panendoscopy including microlaryngoscopy $(p=0.015)$, and for septorhinoplasty $(p=0.007)$. Incision to suture time of most surgeries was overestimated by specialists. The median expected incision to suture time was significantly higher than that measured in case of extirpation of a cervical lymph node $(p=0.024)$, implantation of hypoglossal nerve stimulator $(p=0.039)$, midface reconstruction after bone fractures $(p=0.008)$, panendoscopy including microlaryngoscopy $(p=0.001)$, sialendoscopy $(p=0.046)$ and tonsillectomy $(p=0.001)$. Specialists only underrated real incision to suture time of one-sided neckdissections $(p=0.007)$. In contrast, they significantly underestimated preparation times for implantation of a cochlear implant $(p<0.0001)$, extirpation of a cervical lymph node $(p<0.001)$, implantation of hypoglossal nerve stimulator $(p=0.009)$, midface reconstruction after bone fractures $(p=0.001)$, mastoidectomy $(p=0.045)$, one-sided neck-dissection $(p<0.001)$, sinus surgery $(p<0.001)$, septoplasty $(p=0.009)$, septorhinoplasty $(p<0.0001)$, sialendoscopy $(p=0.036)$, stapes surgery $(p=0.001)$, submandibulectomy $(p=0.040)$, tracheostomy $(p=0.01)$, tympanoplasty $(p<0.0001)$, lateral parotidectomy $(p<0.001)$ and total parotidectomy $(p<0.001)$.

In summary, specialists poorly estimated post-processing time in two out of 22 types of surgeries, incision to suture time in seven out of 22 types and preparation time in 16 out of 22 types of surgeries.

In the case of significantly false estimations, residents generally underestimated overall time.

Thus, the analysis showed an underestimation of post-processing time by residents for midface reconstruction after bone fractures $(p=0.02)$, panendoscopy including microlaryngoscopy $(p<0.001)$, nasal septoplasty $(p=0.002)$, submandibulectomy $(p=0.014)$, tracheostomy $(p=0.001)$ and tonsillectomy with uvulopalatopharyngoplasty $(p=0.001)$. A comparison between objective incision to suture time and estimated time revealed significant underestimations in case of sinus surgery $(p=0.013)$, tonsillectomy $(p=0.04)$ and tonsillectomy with uvulopalatopharyngoplasty $(p<0.001)$.

Residents assume too short preparation times for extirpation of a cervical lymph node $(p<0.0001)$, midface reconstruction $(p<0.0001)$, sinus surgery $(p<0.0001)$, nasal septoplasty $(p<0.0001)$, submandibulectomy $(p<0.0001)$, tracheostomy $(p<0.0001)$ and lateral parotidectomy $(p<0.0001)$.

In summary, residents underestimated objective preparation and post-processing time in seven out of 15 types of surgeries and incision to suture time in three out of 15 different types.

\section{Discussion}


The study revealed that the experience of the individual surgeon who will perform the surgery must be considered when scheduling surgical procedures. Thus, specialists sometimes enter ORs with delay but then conduct the surgery faster than residents. Possible reasons for the specialists' delayed entrance into the $\mathrm{OR}$ are that specialists often have multiple responsibilities such as managing a hospital ward parallel to their consultation hours. Prior examinations already showed that absence of the surgeon is a frequent reason for delays in start time [10]. Therefore, for OR planning, other duties of the intended surgeon, such as meetings and consultation hours, must be considered. Moreover, communication, in terms of feedback in case of being late and reminders of being on time, seems to be a strategy to prevent delay of surgeons $[11,12]$. As a consequence of less routine and practical experience, residents take more time for surgeries. Thus, the surgeon's operating experience should always be respected in OR scheduling. Former studies have ascertained that the presence of residents in the OR results in longer durations of surgeries and increasing costs. The training of residents takes time, however being aware of this fact might help to improve time estimates of planned surgeries [9]. One possible method to save time in ORs may be the improvement of surgical education outside of the OR. Academic hospitals should invest in simulator training programs for residents. Former studies already revealed, that simulator surgery trainings improve the performance of residents in the OR. After simulator training residents operate faster than the control group without training [20-22].

The differences in estimated OR times between residents and specialists can also be explained by different experiences of these subgroups. Residents seem to be more optimistic concerning estimated average incision to suture time, post-processing time and preparation time. Only regarding their own individual duration of surgeries, did specialists expect shorter time periods than residents. Specialists calculate less operating time in six out of 15 types of surgeries. In 4 out of these 6 types of surgeries, their objective OR times are in fact shorter than those of residents. Those four types (nasal septoplasty, tonsillectomy, tonsillectomy with uvulopalatopharyngoplasty, intracapsular tonsillectomy) are typically used for teaching and are often performed by residents. Therefore, it can be hypothesized that specialists are aware of the fact that residents take more time. However, this knowledge does not guarantee that this fact is always taken into account in OR scheduling. There may be a behavioral bias of the planning surgeon.

Predicting the duration of a surgical procedure is somewhat similar to predicting the duration of a sports game. Although you might know that a soccer game takes 90 minutes, it is not possible to know exactly how long the game will last. Furthermore, surgical procedures can go into overtime if unexpected complications or findings occur causing adaptations of the surgical procedure, which requires extra time. On the other hand, there are several factors reducing the expected duration of a surgical case. As the precise estimation of operating times is a prerequisite for efficient OR scheduling, it is important to determine if OR times estimated by surgeons are comparable to "real life" OR times. Our findings suggest that assessments by residents and specialists are reasonably acceptable in terms of cut-seam times, but they often underrate the necessary resources (time, personal) when evaluating times of preparations before cutting and times of post-processing. In our study, preparation times before incision were objectively twice, almost three times, as long as estimated in many types of procedures, e.g., cochlear 
implant and implantation of hypoglossal nerve stimulator, but so were "daily routine" procedures, such as septorhinoplasty or endonasal sinus surgery (Table 1). However, how should they know? They enter the OR for cutting and typically leave after cutting. When surgeons think of a surgical procedure, they mainly think of the process they are taking part in and lose sight of the needs before and after the "surgical act." Wright et al. sought to compare surgeons' time estimates for elective cases with those of commercial scheduling software to assess whether improvements could be made by regression modeling. Encouragingly, surgeons in general topped the commercial scheduling software in scheduling OR times. Individual surgeons were even better compared to the software. A simple model combining surgeons' estimates with the historical data significantly reduced the prediction errors. They also determined that surgeons need an incentive to reduce their errors in estimating duration. As the impact of managed care grows, the incentive to be more accurate may become greater [13]. Whatever system is used to schedule OR times, having more precise estimates of each case's duration and emergence of resources should help reduce underutilization and excess planning of the workday [13-15].

With our data we demonstrate for the first time, that some surgical procedures in ENT are easier to estimate than others, e.g., preparation times, cut-seam times and post-processing times of a tonsillectomy or a septoplasty are easier to estimate than durations of a complicated oncological resection of the head and neck. This corresponds with the findings of Gordon et al., who noted that laparoscopies (the second-most-frequent procedure) at John Hopkin`s Medical Institutions varied by $42 \%$ from the estimated time, whereas hysterectomies, inguinal hernia repairs, and prostatectomies varied by up to $4 \%$ [16]. Our data support the contention that some types of surgeries are inherently difficult to predict.

However, we analyzed nearly 2000 procedures, which allowed us to sustain the mean duration of specific procedures. Despite unpredictable events, such as management problems, patients' transport to the OR or complications/difficulties that may occur during an operation, management and scheduling of the $\mathrm{OR}$ must be done based on that kind of objective information $[17,18]$. The duration of a surgical case depends on patients' individual characteristics of the disease and the surgeon's skill and routine with the procedure performed. This can be shown by the differences in time needed for an ENT resident compared to a specialist (Fig. 1). Vinden et al. determined that a wide range of surgical procedures require significantly more time to perform in teaching than in nonteaching hospitals. They note that the magnitude of this difference is large enough to potentially affect direct and indirect costs, institution and surgeon efficiency, and possibly impact surgical outcomes [19].

\section{Conclusions}

Our data suggest that surgeons do a good job in estimating and scheduling surgical procedures. However, surgeons tend to lose sight of resources and the time necessary to prepare for and perform follow-up course work after surgical procedures. In daily work, routine OR scheduling is usually based on surgeons' appreciations of cut-seam times without realistic perspectives on resources needed for activities before and after the surgery. To avoid errors of estimation regarding pre- and postoperative 
durations, anesthesiologists and OR-assistants (nurses) should be more involved in OR scheduling to avoid excess planning or waste of OR capacity.

Teaching surgery takes time. Different durations of procedures when performed by a resident or a specialist should not be avoided when scheduling OR capacities in a realistic way. Given the magnitude of this difference, the impact of surgical training on health care costs and clinical outcomes should be addressed in future studies. As surgical educators strive to meet the needs of their trainees without compromising economic efficiency or patient safety, this should be an incentive for policy-makers to include the time and money costs of surgical training into funding models.

\title{
List Of Abbreviations
}

\author{
OR operating room \\ S specialist \\ $\mathrm{R} \quad$ resident \\ ENT ear nose throat
}

\section{Declarations}

Ethics approval and informed consent: The study was approved by the ethics committee II of RuprechtKarls-University, Heidelberg, Medical Faculty Mannheim. Ethics application and written statement of the ethics committee is attached to this manuscript as supplementary material declaring, that this study has the character of an acquisition of data without collection of personal data of any patients or other persons. That is why informed consent from any patient/person was not required for acquisition of data. This was approved by the ethics committee. The written statement is attached to this manuscript.

Consent to participate/Consent for publication: The authors declare their consent to participate/for publication

Availability of data and materials: The authors confirm that the data supporting the findings of this study are available within the article [and/or] its supplementary material.

Competing interest: There are no competing interests (financial/non-financial) of the authors.

Funding: There was no funding regarding this study.

Authors` contributions:

LZ was a major contributer in writing the manuscript 
AA was a major contributer in reading/correcting and improving the manuscript

SB was a major contributer in analyzing data statistically and contributed Fig. 1

SL was a major contributer in reading/correcting and improving the manuscript

NR was a major contributer in reading/correcting and improving the manuscript

CS was a major contributer in reading/correcting and improving the manuscript

SvW analyzed and interpreted the scheduling data

CW was a major contributer in analyzing data statistically and contributed Tables 1-3

AL was a major contributer in writing the manuscript

All authors read and approved the final manuscript

Acknowledgements: not applicable

\section{References}

1. Karin Böhm MM. Heft 45 - Ausgaben und Finanzierung des Gesundheitswesens: Robert Koch-Institut; Mai 2009 [Available from: http://www.gbe-bund.de.

2. Waeschle RM, Hinz J, Bleeker F, Sliwa B, Popov A, Schmidt CE, et al. [OR minute myth : Guidelines for calculation of DRG revenues per OR minute]. Anaesthesist. 2016;65(2):137-47.

3. Bercker S, Waschipky R, Hokema F, Brecht W. [Effects of overlapping induction on the utilization of complex operating structures: estimation using the practical application of a simulation model]. Anaesthesist. 2013;62(6):440-6.

4. Grote R, Perschmann S, Walleneit A, Sedlacek B, Leuchtmann D, Menzel M. [Operation room management: from degree of utilization to distribution of capacities. Cost reduction without decreasing productivity in the operation room using a new index]. Anaesthesist. 2008;57(9):882-92.

5. Fugener A, Schiffels S, Kolisch R. Overutilization and underutilization of operating rooms - insights from behavioral health care operations management. Health Care Manag Sci. 2017;20(1):115-28.

6. Hoeper K, Kriependorf M, Felix C, Nyhuis P, Tecklenburg A. [Role-specific targets and teamwork in the operating room]. Anaesthesist. 2017;66(12):953-60.

7. Yule S, Flin R, Paterson-Brown S, Maran N. Non-technical skills for surgeons in the operating room: a review of the literature. Surgery. 2006;139(2):140-9. 
8. Boggs SD, Tsai MH, Urman RD, Association of Anesthesia Clinical D. The Association of Anesthesia Clinical Directors (AACD) Glossary of Times Used for Scheduling and Monitoring of Diagnostic and Therapeutic Procedures. J Med Syst. 2018;42(9):171.

9. Allen RW, Pruitt M, Taaffe KM. Effect of Resident Involvement on Operative Time and Operating Room Staffing Costs. J Surg Educ. 2016;73(6):979-85.

10. Han SJ, Rolston JD, Zygourakis CC, Sun MZ, McDermott MW, Lau CY, et al. Preventing Delays in FirstCase Starts on the Neurosurgery Service: A Resident-Led Initiative at an Academic Institution. J Surg Educ. 2016;73(2):291-5.

11. Overdyk FJ, Harvey SC, Fishman RL, Shippey F. Successful strategies for improving operating room efficiency at academic institutions. Anesth Analg. 1998;86(4):896-906.

12. Fezza M, Palermo GB. Simple solutions for reducing first-procedure delays. AORN J. 2011;93(4):4504.

13. Wright IH, Kopperberg C, Bonar BA, Basheim G. Statistical modeling to predict elective surgery time. Anesthesiology. 1996; 85: 1235-45

14. Magerlein JM, Martin JB: Surgical demand scheduling: A review. Health Serv Res 1978; 13:418-33

15. Hamilton DM, Breslawski S: Operating room scheduling, Factors to consider. AORN J 1994; 59:665-8, $671-80$

16. Gordon T, Paul S, Lyles A, Fountain J: Surgical unit time utilization review: Resource utilization and management implications. J Med Syst 1988; 12:169-79

17. Altair da Silva C Jr.: Assessment of operative time of multiple surgical specialties in a public university hospital. Health Economics and Management. 2017; 15(2):200-5

18. van Eijk PR, van Veen-Berkx E, Kazemier G, Eijkemans MJ. Effect of individual surgeons and anesthesiologists on operating room time. Anesth Analg. 2016; 123(2):445-51

19. Vinden C, Malthaner R, McGee J, McClure JA, Winick-Ng J, Liu K, Nash DM, Welk B, Dubois L. Teaching surgery takes time: the impact of surgical education on time in the operating room. Can $\mathrm{J}$ Surg, Vol. 59, No. 2, April 2016

20. Fried MP, Uribe JI, Sadoughi B. The role of virtual reality in surgical training in otorhinolaryngology. Curr Opin Otolaryngol Head Neck Surg. 2007;15(3):163-9.

21. Pollei TR, Barrs DM, Hinni ML, Bansberg SF, Walter LC. Operative time and cost of resident surgical experience: effect of instituting an otolaryngology residency program. Otolaryngol Head Neck Surg. 2013;148(6):912-8. 
22. Seymour NE, Gallagher AG, Roman SA, O'Brien MK, Bansal VK, Andersen DK, et al. Virtual reality training improves operating room performance: results of a randomized, double-blinded study. Ann Surg. 2002;236(4):458-63; discussion 63-4.

\section{Tables}


: Durations of preparations for different surgical procedures. Given are median values, minima and maxima for residents (R), ists $(\mathrm{S})$ and $\mathrm{p}$ values deriving from $\mathrm{U}$ tests. Sample sizes in parantheses.

\begin{tabular}{|c|c|c|c|c|c|c|c|}
\hline Il procedure & & $\begin{array}{l}\text { Patient's entrance - surgeon's } \\
\text { entrance }\end{array}$ & Setup & $\begin{array}{l}\text { Surgical } \\
\text { preparation }\end{array}$ & $\begin{array}{l}\text { Incision- } \\
\text { suture }\end{array}$ & $\begin{array}{l}\text { Post } \\
\text { processing }\end{array}$ & $\begin{array}{l}\text { Surgical } \\
\text { post } \\
\text { processing }\end{array}$ \\
\hline $\begin{array}{l}\text { revision after bone } \\
\text { əs }\end{array}$ & $\begin{array}{c}\mathrm{R} \\
(17) \\
\mathrm{S} \\
(22)\end{array}$ & $\begin{array}{l}0(0-20) \\
0(0-12) \\
p=0.8970\end{array}$ & $\begin{array}{l}23(14- \\
61) \\
23(13- \\
61) \\
p= \\
0.6808\end{array}$ & $\begin{array}{l}16(0-53) \\
15(1-36) \\
p=0.7558\end{array}$ & $\begin{array}{l}73(1-165) \\
75(34-255) \\
p=0.8873\end{array}$ & $\begin{array}{l}14(4-36) \\
13.5(7-30) \\
p=0.9773\end{array}$ & $\begin{array}{l}2(0-5) \\
2(0-23) \\
p=0.9311\end{array}$ \\
\hline sal endoscopic sinus & $\begin{array}{c}\mathrm{R} \\
(46) \\
\mathrm{S} \\
(167)\end{array}$ & $\begin{array}{l}0(0-19) \\
0(0-23) \\
p=0.0182\end{array}$ & $\begin{array}{l}19(9-39) \\
18(1-48) \\
\mathrm{p}= \\
0.9375\end{array}$ & $\begin{array}{l}14(1-35) \\
13(0-101) \\
p=0.3717\end{array}$ & $\begin{array}{l}115.5(41- \\
603) \\
68(9-244) \\
p<0.0001\end{array}$ & $\begin{array}{l}12.5(5-26) \\
13.5(4-56) \\
p=0.0672\end{array}$ & $\begin{array}{l}2(0-9) \\
2(0-29) \\
p=0.7524\end{array}$ \\
\hline eptomplasty & $\begin{array}{c}\mathrm{R} \\
(77) \\
\mathrm{S} \\
(73) \\
\end{array}$ & $\begin{array}{l}0(0-15) \\
0(0-13) \\
p=0.0326\end{array}$ & $\begin{array}{l}16(4-53) \\
14(4-36) \\
p= \\
0.0871\end{array}$ & $\begin{array}{l}11(0-40) \\
9(0-24) \\
p=0.0883\end{array}$ & $\begin{array}{l}73(28-160) \\
53(7-203) \\
p<0.0001\end{array}$ & $\begin{array}{l}15(5-40) \\
14(3-29) \\
p=0.1837\end{array}$ & $\begin{array}{l}2(0-8) \\
2(0-11) \\
p=0.9508\end{array}$ \\
\hline ıdibulectomy & $\begin{array}{l}\mathrm{R} \\
(10) \\
\mathrm{S}(2)\end{array}$ & $\begin{array}{l}0(0-12) \\
5(5-5) \\
p=0.1587\end{array}$ & $\begin{array}{l}20.5(14- \\
32) \\
23(19- \\
27) \\
p= \\
1.0000\end{array}$ & $\begin{array}{l}18(3-26) \\
12.5(12-13) \\
p=0.3877\end{array}$ & $\begin{array}{l}76(45-110) \\
57.5(43-72) \\
p=0.2374\end{array}$ & $\begin{array}{l}13(8-20) \\
9.5(9-10) \\
p=0.2785\end{array}$ & $\begin{array}{l}2.5(1-6) \\
3(3-3) \\
p=0.9128\end{array}$ \\
\hline sstomy & $\begin{array}{c}\mathrm{R} \\
(27) \\
\mathrm{S} \\
(13)\end{array}$ & $\begin{array}{l}0(0-13) \\
0(0-3) \\
p=0.6979\end{array}$ & $\begin{array}{l}28(10- \\
56) \\
19(13- \\
28) \\
p= \\
0.7362 \\
\end{array}$ & $\begin{array}{l}15.5(2-31) \\
19(13-28) \\
p=0.1680\end{array}$ & $\begin{array}{l}52(6-96) \\
45(26-78) \\
p=0.5345\end{array}$ & $\begin{array}{l}16.5(5-58) \\
17(13-22) \\
p=0.8551\end{array}$ & $\begin{array}{l}3.5(0-10) \\
3(2-4) \\
p=0.7028\end{array}$ \\
\hline $\begin{array}{l}\text { ctomy with } \\
\text { laryngoplasty }\end{array}$ & $\begin{array}{c}\mathrm{R} \\
(42) \\
\mathrm{S} \\
(21)\end{array}$ & $\begin{array}{l}0(0-10 \\
0(0-16) \\
p=0.0094\end{array}$ & $\begin{array}{l}7.5(3- \\
21) \\
9(4-19) \\
p= \\
0.0068 \\
\end{array}$ & $\begin{array}{l}4(0-12) \\
3(1-11) \\
p=0.3687\end{array}$ & $\begin{array}{l}66(35-112) \\
49(14-130) \\
p=0.0018\end{array}$ & $\begin{array}{l}17(0-55) \\
13(5-44) \\
p=0.2061\end{array}$ & $\begin{array}{l}2(0-9) \\
2(0-4) \\
p=0.0154\end{array}$ \\
\hline parotidectomies & $\begin{array}{l}R(6) \\
S \\
(49)\end{array}$ & $\begin{array}{l}0(0-0) \\
0(0-39) \\
p=0.3080\end{array}$ & $\begin{array}{l}34(18- \\
39) \\
26.5(5- \\
54) \\
p= \\
0.4817\end{array}$ & $\begin{array}{l}32(13-34) \\
23(1-44) \\
p=0.1675\end{array}$ & $\begin{array}{l}121(58-176) \\
124(22-280) \\
p=0.6560\end{array}$ & $\begin{array}{l}8(5-13) \\
16(7-55) \\
p=0.0016\end{array}$ & $\begin{array}{l}2(1-8) \\
4(0-11) \\
p=0.1765\end{array}$ \\
\hline
\end{tabular}


Page 15/19 
ə 2: Sums of durations. Given are median values, minima and maxima for specialists (S), residents (R) and p values deriving from U tests.

\begin{tabular}{|c|c|c|c|c|c|}
\hline ical procedure & & $\begin{array}{l}\text { Whole } \\
\text { OP }\end{array}$ & $\begin{array}{l}\text { Setup }+ \text { post } \\
\text { processing }\end{array}$ & $\begin{array}{l}\text { Surgical preparation }+ \text { surgical } \\
\text { post processing }\end{array}$ & $\begin{array}{l}\text { Surgical preparation }+ \text { incision-suture }+ \\
\text { surgical post processing }\end{array}$ \\
\hline $\begin{array}{l}\text { pation of a cervical } \\
\text { a node }\end{array}$ & $\begin{array}{l}\mathrm{R} \\
(36) \\
\mathrm{S} \\
(29)\end{array}$ & $\begin{array}{l}83.5(43- \\
165) \\
75(45- \\
120) \\
p= \\
0.1446\end{array}$ & $\begin{array}{l}32(17-84) \\
36(21-63) \\
p=0.4717\end{array}$ & $\begin{array}{l}17(3-42) \\
17(2-31) \\
p=0.7771\end{array}$ & $\begin{array}{l}66.5(36-130) \\
58(33-110) \\
p=0.1102\end{array}$ \\
\hline $\begin{array}{l}\text { ice revision after } \\
\text { fractures }\end{array}$ & $\begin{array}{l}\mathrm{R} \\
(17) \\
\mathrm{S} \\
(22)\end{array}$ & $\begin{array}{l}121(32- \\
215) \\
109(57- \\
341) \\
p= \\
0.9435\end{array}$ & $\begin{array}{l}42(29-75) \\
38.5(21-86) \\
p=0.7020\end{array}$ & $\begin{array}{l}17.5(2-57) \\
17(2-45) \\
p=0.8243\end{array}$ & $\begin{array}{l}87(11-192) \\
83(50-300) \\
p=0.7988\end{array}$ \\
\hline $\begin{array}{l}\text { Jlaryngoscopy with } \\
\text { adoscopy }\end{array}$ & $\begin{array}{l}\mathrm{R} \\
(198) \\
\mathrm{S} \\
(180)\end{array}$ & $\begin{array}{l}59(8- \\
176) \\
52.5(24- \\
216) \\
\mathrm{p}= \\
0.0013\end{array}$ & $\begin{array}{l}25(6-97) \\
26(8-77) \\
p=0.1514\end{array}$ & $\begin{array}{l}6(0-53) \\
5(0-40) \\
p=0.0116\end{array}$ & $\begin{array}{l}39(7-132) \\
30(6-175) \\
p<0.0001\end{array}$ \\
\hline $\begin{array}{l}\text { nasal endoscopic } \\
\text { surgery }\end{array}$ & $\begin{array}{l}\mathrm{R} \\
(46) \\
\mathrm{S} \\
(167)\end{array}$ & $\begin{array}{l}148 \text { (68- } \\
629) \\
98.5(31- \\
253) \\
\mathrm{p}< \\
0.0001\end{array}$ & $\begin{array}{l}31(20-54) \\
34(12-70) \\
p=0.0688\end{array}$ & $\begin{array}{l}16(2-43) \\
15(0-104) \\
p=0.6013\end{array}$ & $\begin{array}{l}132.5(48-613) \\
81.5(12-235) \\
\mathrm{p}<0.0001\end{array}$ \\
\hline l septomplasty & $\begin{array}{l}\mathrm{R} \\
(77) \\
\mathrm{S} \\
(73)\end{array}$ & $\begin{array}{l}107(64- \\
202) \\
80.5(19- \\
244) \\
\mathrm{p}< \\
0.0001\end{array}$ & $\begin{array}{l}32(12-67) \\
27(13-52) \\
p=0.0109\end{array}$ & $\begin{array}{l}13(2-42) \\
11(1-29) \\
p=0.1604\end{array}$ & $\begin{array}{l}86(30-171) \\
62.5(4-229) \\
p<0.0001\end{array}$ \\
\hline ıandibulectomy & $\begin{array}{l}\mathrm{R} \\
(10) \\
\mathrm{S}(2)\end{array}$ & $\begin{array}{l}104.5 \\
(89-150) \\
90(71- \\
109) \\
\mathrm{p}= \\
0.5912 \\
\end{array}$ & $\begin{array}{l}33.5(26-50) \\
32.5(28-37) \\
p=0.8266\end{array}$ & $\begin{array}{l}21(4-30) \\
15.5(15-16) \\
p=0.4513\end{array}$ & $\begin{array}{l}87.5(72-135) \\
73(59-87) \\
p=0.2819\end{array}$ \\
\hline llectomy & $\begin{array}{l}\mathrm{R} \\
(92) \\
\mathrm{S} \\
(49)\end{array}$ & $\begin{array}{l}62(37- \\
165) \\
46(7- \\
85) \\
p< \\
0.0001 \\
\end{array}$ & $\begin{array}{l}22.5(8-45) \\
23(6-49) \\
p=0.9806\end{array}$ & $\begin{array}{l}5(0-21) \\
5(0-43) \\
p=0.9197\end{array}$ & $\begin{array}{l}44(19-137) \\
28(19-67) \\
p<0.0001\end{array}$ \\
\hline reostomy & $\begin{array}{l}\mathrm{R} \\
(27) \\
\mathrm{S} \\
(13)\end{array}$ & $\begin{array}{l}78.5(6- \\
179) \\
45(26- \\
109) \\
p= \\
0.2332\end{array}$ & $\begin{array}{l}14(0-114) \\
0(0-45) \\
p=0.2173\end{array}$ & $\begin{array}{l}18(6-38) \\
22(15-32) \\
p=0.7362\end{array}$ & $\begin{array}{l}67.5(12-127) \\
55(32-95) \\
p=0.2573\end{array}$ \\
\hline $\begin{array}{l}\text { llectomy with } \\
\text { palaryngoplasty }\end{array}$ & $\begin{array}{l}\mathrm{R} \\
(42) \\
\mathrm{S} \\
(21)\end{array}$ & $\begin{array}{l}92(63- \\
157) \\
68(32- \\
180)\end{array}$ & $\begin{array}{l}25(4-63) \\
24(13-60) \\
p=0.8609\end{array}$ & $\begin{array}{l}6(2-15) \\
5(2-11) \\
p=0.0399\end{array}$ & $\begin{array}{l}71.5(40-122) \\
54(19-139) \\
\mathrm{p}=0.0010\end{array}$ \\
\hline
\end{tabular}




\begin{tabular}{|c|c|c|c|c|c|}
\hline & & $\begin{array}{l}p= \\
0.004\end{array}$ & & & \\
\hline al parotidectomies & $\begin{array}{l}\text { R (6) } \\
\text { S } \\
(49)\end{array}$ & $\begin{array}{l}164.5 \\
(84-219) \\
162(68- \\
328) \\
p= \\
0.818\end{array}$ & $\begin{array}{l}41(26-48) \\
44(16-78) \\
p=0.2240\end{array}$ & $\begin{array}{l}32(16-42) \\
28(3-50) \\
p=0.6229\end{array}$ & $\begin{array}{l}158(74-211) \\
146(53-308) \\
p=0.6365\end{array}$ \\
\hline
\end{tabular}


ble 3: Subjective vs. objective "durations of preparations for different surgical procedures" (estimation done by ENT-specialists). n.a.: = no ta available

\begin{tabular}{|c|c|c|c|c|}
\hline \multirow{2}{*}{$\begin{array}{l}\text { Irgical procedure } \\
\text { chlear Implant }\end{array}$} & \multicolumn{2}{|c|}{ Specialists } & \multicolumn{2}{|c|}{ Residents } \\
\hline & $\begin{array}{l}\text { obj. (92) } \\
\text { sub. (8) }\end{array}$ & $\begin{array}{l}56.5(12-107) \\
20.0(15-30) \\
p<0.0001\end{array}$ & & n.a. \\
\hline tirpation of a cervical lymph node & $\begin{array}{l}\text { obj. (28) } \\
\text { sub. (9) }\end{array}$ & $\begin{array}{l}35.0(11-89) \\
20.0(19-30) \\
p=0.0002\end{array}$ & $\begin{array}{l}\text { obj. (34) } \\
\text { sub. (14) }\end{array}$ & $\begin{array}{l}34.5(10-80) \\
10.0(5-25) \\
p<0.0001\end{array}$ \\
\hline plantation of hypoglossal nerve stimulator & $\begin{array}{l}\text { obj. (31) } \\
\text { sub. (6) }\end{array}$ & $\begin{array}{l}66.0(4-123) \\
30.0(15-60) \\
\mathrm{p}=0.0094\end{array}$ & & n.a. \\
\hline dface revision after bone fractures & $\begin{array}{l}\text { obj. (44) } \\
\text { sub. (8) }\end{array}$ & $\begin{array}{l}37(15-97) \\
17.5(10-30) \\
\mathrm{p}=0.0006\end{array}$ & $\begin{array}{l}\text { obj. (16) } \\
\text { sub. (14) }\end{array}$ & $\begin{array}{l}39.5(15-114) \\
15(5-20) \\
p<0.0001\end{array}$ \\
\hline crolaryngoscopy with panendoscopy & $\begin{array}{l}\text { obj. (177) } \\
\text { sub. (9) }\end{array}$ & $\begin{array}{l}10(1-58) \\
10(5-20) \\
\mathrm{p}=0.8863\end{array}$ & $\begin{array}{l}\text { obj. (191) } \\
\text { subj. (16) }\end{array}$ & $\begin{array}{l}12(2-97) \\
10(5-45) \\
p=0.2095\end{array}$ \\
\hline ıstoidectomy & $\begin{array}{l}\text { obj. (13) } \\
\text { sub. (8) }\end{array}$ & $\begin{array}{l}40(9-96) \\
15(15-25) \\
\mathrm{p}=0.0448\end{array}$ & & n.a. \\
\hline ilateral neck dissection & $\begin{array}{l}\text { obj. (11) } \\
\text { sub. (9) }\end{array}$ & $\begin{array}{l}49(20-102) \\
20(15-30) \\
\mathrm{p}=0.0005\end{array}$ & & n.a. \\
\hline donasal endoscopic sinus surgery & $\begin{array}{l}\text { obj. (162) } \\
\text { sub. (9) }\end{array}$ & $\begin{array}{l}31(2-111) \\
15(15-25) \\
\mathrm{p}=0.0002\end{array}$ & $\begin{array}{l}\text { obj. (46) } \\
\text { sub. (15) }\end{array}$ & $\begin{array}{l}31.5(14-73) \\
15(5-20) \\
\mathrm{p}<0.0001\end{array}$ \\
\hline sal septoplasty & $\begin{array}{l}\text { obj. (72) } \\
\text { sub. (10) }\end{array}$ & $\begin{array}{l}24(5-59) \\
15(10-20) \\
\mathrm{p}=0.0092\end{array}$ & $\begin{array}{l}\text { obj. (75) } \\
\text { sub. (15) }\end{array}$ & $\begin{array}{l}26(6-86) \\
15(5-20) \\
p<0.0001 \\
\end{array}$ \\
\hline ptorhinoplasty & $\begin{array}{l}\text { obj. (165) } \\
\text { sub. (9) }\end{array}$ & $\begin{array}{l}36(7-103) \\
15(10-25) \\
\mathrm{p}<0.0001 \\
\end{array}$ & & n.a. \\
\hline lendoscopy & $\begin{array}{l}\text { obj. (16) } \\
\text { sub. (9) }\end{array}$ & $\begin{array}{l}27(14-38) \\
15(10-30) \\
p=0.0355\end{array}$ & & n.a. \\
\hline ipesplasty & $\begin{array}{l}\text { obj. (8) } \\
\text { sub. (7) }\end{array}$ & $\begin{array}{l}50(23-87) \\
20(15-20) \\
\mathrm{p}=0.0013\end{array}$ & & n.a. \\
\hline bmandibulectomy & $\begin{array}{l}\text { obj. (2) } \\
\text { sub. (9) }\end{array}$ & $\begin{array}{l}35.5(32-39) \\
20(5-30) \\
\mathrm{p}=0.0398\end{array}$ & $\begin{array}{l}\text { obj. (10) } \\
\text { sub. (13) }\end{array}$ & $\begin{array}{l}38(17-56) \\
15(5-25) \\
\mathrm{p}=0.0001\end{array}$ \\
\hline æcheostomy & $\begin{array}{l}\text { obj. (3) } \\
\text { sub. (9) }\end{array}$ & $\begin{array}{l}48(36-56) \\
15(10-20) \\
\mathrm{p}=0.0101\end{array}$ & $\begin{array}{l}\text { obj. (12) } \\
\text { sub. (17) }\end{array}$ & $\begin{array}{l}48(17-72) \\
15(6-60) \\
\mathrm{p}<0.0001\end{array}$ \\
\hline mpanoplasty & $\begin{array}{l}\text { obj. (140) } \\
\text { sub. (8) }\end{array}$ & $\begin{array}{l}38(7-102) \\
17.5(10-20) \\
\mathrm{p}<0.0001\end{array}$ & & n.a. \\
\hline teral parotidectomy & $\begin{array}{l}\text { obj. (48) } \\
\text { sub. (8) }\end{array}$ & $\begin{array}{l}49.5(8-90) \\
22.5(15-30) \\
\mathrm{p}=0.0001\end{array}$ & $\begin{array}{l}\text { obj. (6) } \\
\text { sub. (14) }\end{array}$ & $\begin{array}{l}66(31-73) \\
15(5-30) \\
\mathrm{p}=0.0006\end{array}$ \\
\hline tal parotidectomy & $\begin{array}{l}\text { obj. (10) } \\
\text { sub. (7) }\end{array}$ & $\begin{array}{l}66(43-175) \\
25.0(20-35) \\
p=0.0007\end{array}$ & & n.a. \\
\hline
\end{tabular}




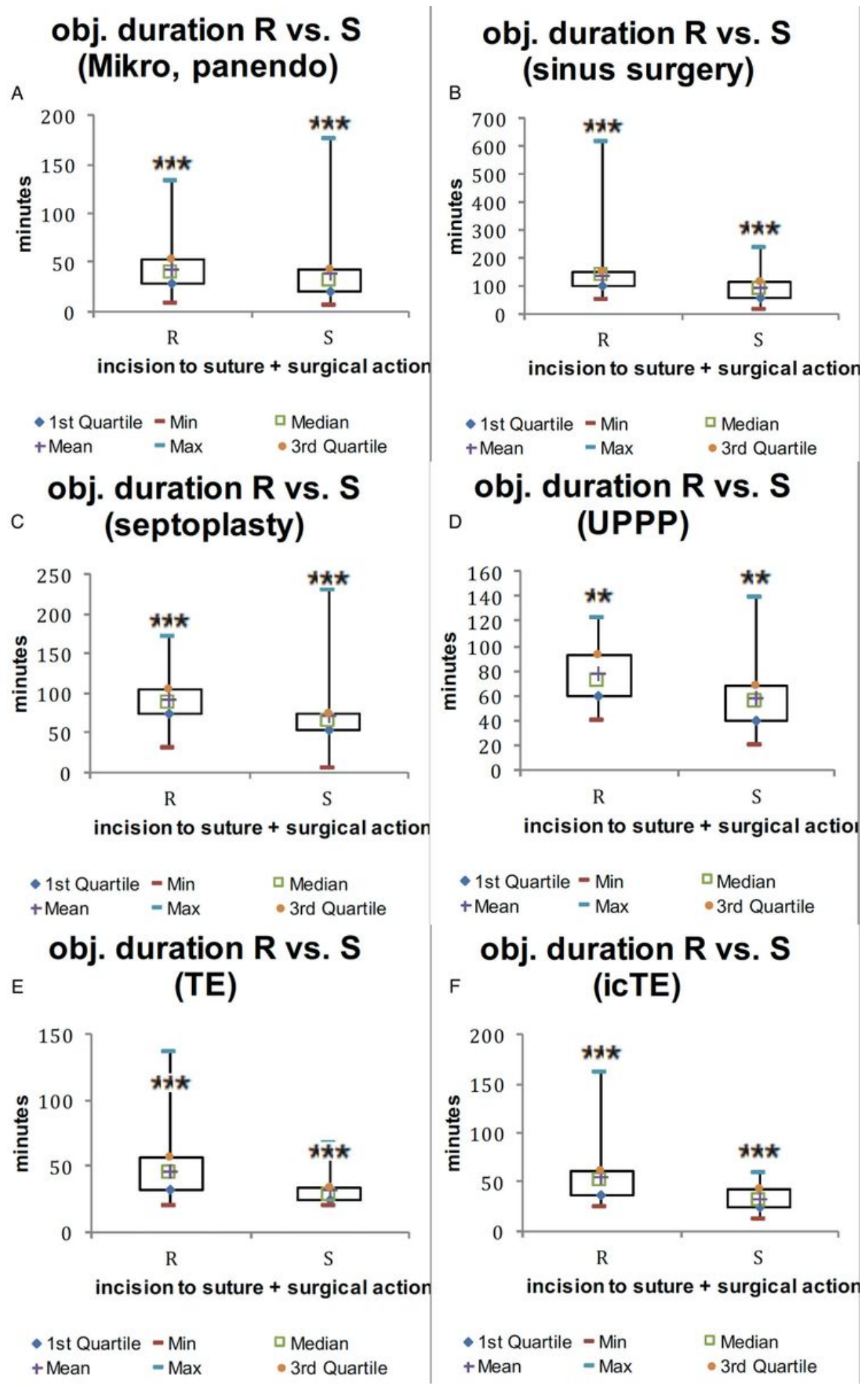

Figure 1

Evaluation of objective cut-seam times performed by residents $(R)$ and specialists $(S)$ for different procedures in the field of ENT surgery (A: panendoscopy including microlaryngoscopy; B: sinus surgery; C: septoplasty; D: uvulopalatoplasty; E: tonsillectomy; F: intracapsular tonsillectomy/tonsillotomy). 